\title{
Clinical utility gene card for: Nemaline myopathy - update 2015
}

\author{
Kristen J Nowak ${ }^{1,4}$, Mark R Davis ${ }^{2,4}$, Carina Wallgren-Pettersson ${ }^{3}$, Phillipa J Lamont ${ }^{2}$ and Nigel G Laing L $^{\star, 1}$
}

European Journal of Human Genetics (2015) 23, doi:10.1038/ejhg.2015.12; published online 25 February 2015

Update to: European Journal of Human Genetics (2012) 20, doi:10.1038/ejhg.2012.70; published online 18 April 2012

\section{DISEASE CHARACTERISTICS}

\subsection{Name of the disease (synonyms)}

Nemaline myopathy (NEM1-NEM10).

Includes nemaline myopathy with excess thin filaments/actin aggregates; nemaline myopathy with cores; nemaline myopathy with intranuclear rods; and Amish nemaline myopathy.

\subsection{OMIM\# of the disease}

NEM1 - 609284; NEM2 - 256030; NEM3 - 161800; NEM4 - 609285; NEM5 - 605355; NEM6 - 609273; NEM7 - 610687; NEM8 - 615348; NEM9 - 615731; NEM10 - 616165.

1.3 Name of the analysed genes or DNA/chromosome segments Slow muscle $\alpha$-tropomyosin (TPM3) - NEM1.

Nebulin (NEB) - NEM2.

Skeletal muscle $\alpha$-actin (ACTA1) - NEM3.

$\beta$-tropomyosin (TPM2) - NEM4.

Slow muscle troponin-T (TNNT1) - NEM5.

Kelch-repeat and BTB (POZ) Domain containing 13 (KBTBD13)

- NEM6.

Skeletal muscle cofilin (CFL2) - NEM7.

KELCH-like 40 (KLHL40) - NEM8.

KELCH-like 41 (KLHL41) - NEM9.

Leiomodin 3 (LMOD3) - NEM10.

1.4 OMIM\# of the gene(s)

TPM $3={ }^{\star} 191030 ; \quad \mathrm{NEB}={ }^{\star} 161650 ; \quad$ ACTA $1={ }^{\star} 102610 ; \quad$ TPM $2=$ ${ }^{\star} 190990 ; \mathrm{TNNT} 1={ }^{\star} 191041 ; \mathrm{KBTBD} 13={ }^{\star} 613727$; CFL $2={ }^{\star} 601443$; KLHL40 $={ }^{\star} 615340 ;$ KLHL41 $={ }^{\star} 607701 ;$ LMOD3 $={ }^{\star} 616112$.

\subsection{Mutational spectrum}

TPM3: mainly dominant, missense variants; ${ }^{1,2}$ however, some recessive variants have been described. ${ }^{3,4}$ A 1 bp recessive deletion occurs as a founder variant in the Turkish population. ${ }^{5}$

NEB: all of the over 140 variants identified to date are recessive and the patients are usually compound heterozygous. The majority of the variants are either frameshift or nonsense variants, but also missense variants, and point variants and deletions affecting splice sites are known. ${ }^{6,7}$ An in-frame deletion of exon 55 is present in the Ashkenazi Jewish population at a carrier frequency of $\sim 1$ in $108 .{ }^{8}$ Some patients present with a distal myopathy, with their skeletal muscle biopsies containing nemaline bodies, both nemaline bodies and cores, or no nemaline bodies. ${ }^{9,10}$ Rare cases of core-rod myopathy with generalised muscle weakness may also be caused by NEB variants. ${ }^{11}$

ACTA1: over 200 different variants identified, with the majority causing nemaline myopathy, or nemaline myopathy with other features (eg cores, actin aggregates, intranuclear rods and zebra bodies). ${ }^{12}$ Of these, most variants are dominant, missense, and have arisen de novo. ${ }^{13}$ About $10 \%$ are recessive variants. Most recessive variants are genetic or functional null variants ${ }^{13}$ but recently recessive ACTA1 disease with retention of skeletal muscle actin expression was described in a family presenting with a rigid spine syndrome. ${ }^{14}$ Dominant inheritance is less common, and only seen in families with a milder phenotype. ${ }^{13}$ Somatic mosaicism is possible with dominant variants. ${ }^{15}$ Some variants can cause hypercontractile skeletal muscle rather than weakness. ${ }^{16}$

TPM2: Two heterozygous, dominant missense variants causing nemaline myopathy are known. ${ }^{17}$ Also a homozygous null variant in a patient with nemaline and Escobar syndrome, ${ }^{18}$ and a dominant heterozygous variant in a mother with nemaline myopathy and her daughter with cap myopathy ${ }^{19}$ have been identified. A K7del variant was identified in a family with nemaline bodies and minicores (presenting as a distal myopathy), and also in four unrelated families with distal arthrogryposis type 7 with nemaline bodies. ${ }^{20}$ The K7del variant also causes progressive skeletal muscle contractures, most probably because of the hypercontractility caused by the mutant protein in nemaline myopathy and/or core-rod myopathy patients. ${ }^{21}$

TNNT1: a recessive nonsense founder variant is present in the Old Order Amish population. This produces a characteristic progressive nemaline myopathy with tremors and contractures. ${ }^{22}$ TNNT1 variants have now been identified outside the Amish population. ${ }^{23}$

KBTBD13: three dominant missense variants have been identified. ${ }^{24}$ There was phenotypic variability, with some variant carriers exhibiting only very mild proximal leg weakness on targeted examination.

CFL2: homozygous missense variants have been identified in two families, ${ }^{25,26}$ and a homozygous $4 \mathrm{bp}$ deletion identified in another family. ${ }^{27}$ The severity of the disease is greater in the family with the homozygous null variant.

KLHL40: homozygous or compound heterozygous variants (mainly missense, but also frameshift, splice site and nonsense variants) cause

${ }^{1}$ Centre for Medical Research, The University of Western Australia and the Harry Perkins Institute of Medical Research, QEII Medical Centre, Nedlands, Western Australia, Australia; ${ }^{2}$ Department of Diagnostic Genomics, Neurogenetics Laboratory, QEII Medical Centre, Nedlands, Western Australia, Australia; ${ }^{3}$ Department of Medical Genetics, The Folkhälsan Institute of Genetics, Haartman Institute, University of Helsinki, Helsinki, Finland

${ }^{4}$ These authors contributed equally to this work.

*Correspondence: Professor NG Laing, Harry Perkins Institute of Medical Research, QQ Block, QEll Medical Centre, Nedlands, Western Australia 6009, Australia. Tel: +61 86151 0741; Fax: +61 86151 0701; E-mail: Nigel.Laing@uwa.edu.au

Received 30 July 2014; revised 16 December 2014; accepted 13 January 2015; published online 25 February 2015 
severe autosomal recessive nemaline myopathy with prenatal onset of symptoms, including foetal akinesia or hypokinesia and contractures. ${ }^{28}$ At birth, the children may have fractures, respiratory failure and severe swallowing difficulties. ${ }^{28}$

KLHL41: Recessive homozygous or compound heterozygous variants have been reported, with frameshift variants leading to a severe phenotype with neonatal death, and missense variants compatible with survival into late childhood or early adulthood. ${ }^{29}$

LMOD3: Recessive homozygous and compound heterozygous variants cause severe, usually lethal nemaline myopathy. ${ }^{30}$

Regularly updated variant databases exist for ACTA1, CFL2, KBTBD13, KLHL40, NEB, TNNT1, TPM2 and TPM3 at the Leiden Muscular Dystrophy pages (http://www.dmd.nl).

\subsection{Analytical methods}

The main analytical method has been bi-directional Sanger sequencing of the entire coding region of the individual genes. If the family structure is amenable, linkage analysis for $N E B$ may be useful to prescreen, because of the large size of the gene. Next-generation sequencing now allows for simultaneous analysis of all genes in a patient through whole-exome sequencing. Alternatively sub-exomic sequencing using a panel of selected genes can include all known nemaline myopathy genes. ${ }^{31}$ It should be noted however that limitations of current high throughput sequencing technologies prevent complete screening of all exons in all genes (eg, regions of genes that have high GC content or are repetitive).

\subsection{Analytical validation}

Variants should be confirmed by resequencing using a fresh dilution of genomic DNA. Putative variants identified through next-generation sequencing methods should be confirmed by Sanger sequencing. Special care should be taken in interpreting missense variants in the nebulin gene as affecting function. ${ }^{10}$

1.8 Estimated frequency of the disease (incidence at birth ('birth prevalence') or population prevalence)

For the most part, the frequency of the disease is unknown. In Finland, the birth incidence has been estimated to be 0.02 per 1000 live births. ${ }^{32}$ De novo dominant variants in ACTA1 and recessive variants in $N E B$ are the most common causes of NEM. ${ }^{33,34}$

\subsection{If applicable, prevalence in the ethnic group of investigated person}

Recessive founder variants are known to exist in particular genes in specific populations: TNNT1 in the Amish; ${ }^{22}$ NEB in the Ashkenazi Jewish $^{8}$ and in the Finnish population. ${ }^{10}$ ACTA1 in the Pakistani community in England, and in French and Spanish Roma; ${ }^{13}$ TPM3 in the Turkish population; ${ }^{5}$ and KLHL40 in Japanese persons. ${ }^{28}$ These specific cases aside, no clear differences in prevalence rates are known between different ethnic groups.

\subsection{Diagnostic setting}

\begin{tabular}{lll}
\hline & Yes & No \\
A. (Differential) diagnostics & $\bigotimes$ & $\square$ \\
B. Predictive testing & $\bigotimes$ & $\square$ \\
C. Risk assessment in relatives & $\bigotimes$ & $\square$ \\
D. Prenatal & $\bigotimes$ & $\square$
\end{tabular}

Comment: requests for predictive testing are not common because of the early onset of the disease, but may be offered in families with childhood or late-onset forms of the disease.

\section{TEST CHARACTERISTICS}

\begin{tabular}{|c|c|c|c|c|}
\hline & \multicolumn{2}{|c|}{ Genotype or disease } & \multirow{2}{*}{$\begin{array}{l}\text { A: True positives } \\
\text { B: False positives }\end{array}$} & \multirow{2}{*}{$\begin{array}{l}\text { C: False negative } \\
\text { D: True negative }\end{array}$} \\
\hline & Present & Absent & & \\
\hline \multicolumn{5}{|l|}{ Test } \\
\hline \multirow[t]{2}{*}{ Positive } & $A$ & $B$ & Sensitivity: & $A /(A+C)$ \\
\hline & & & Specificity: & $D /(D+B)$ \\
\hline \multirow[t]{2}{*}{ Negative } & C & $\mathrm{D}$ & Positive predictive value: & $A /(A+B)$ \\
\hline & & & Negative predictive value: & $\mathrm{D} /(\mathrm{C}+\mathrm{D})$ \\
\hline
\end{tabular}

\subsection{Analytical sensitivity \\ (proportion of positive tests if the genotype is present) $100 \%$.}

\subsection{Analytical specificity \\ (proportion of negative tests if the genotype is not present) $100 \%$.}

\subsection{Clinical Sensitivity}

(proportion of positive tests if the disease is present)

The clinical sensitivity is dependent on factors such as age, inheritance pattern and additional clinical features. Because of the genetic heterogeneity, and particularly the difficulty of screening $N E B$, full screening of all known nemaline myopathy genes has historically not been possible. However, next-generation technologies are now getting closer to such screening. If full screening were to be undertaken, it may be estimated that $\sim 75 \%$ of patients would have a variant(s) identified. ${ }^{6,13}$

\subsection{Clinical specificity}

(proportion of negative tests if the disease is not present)

The clinical specificity can be dependent on variable factors such as age or family history. In such cases a general statement should be given, even if a quantification can only be made case by case. Probably $100 \%$.

2.5 Positive clinical predictive value (life time risk of developing the disease if the test is positive)

Nearly $100 \%$. Potential incomplete penetrance has been suggested for certain ACTA1 variants ${ }^{35}$ and a very mild phenotype can be associated with some $K B T B D 13$ variants. $^{24}$

2.6 Negative clinical predictive value (probability of not developing the disease if the test is negative)

Assume an increased risk based on family history for a nonaffected person. Allelic and locus heterogeneity may need to be considered.

Index case in that family had been tested:

Approximately $100 \%$.

Index case in that family had not been tested:

No predictive tests are usually performed in such cases. 


\section{CLINICAL UTILITY}

3.1 (Differential) diagnostics: The tested person is clinically affected (To be answered if in 1.10 'A' was marked)

\subsubsection{Can a diagnosis be made other than through a genetic test?}

\begin{tabular}{ll}
\hline No. & $\square$ \\
& (continue with 3.1.4) \\
Yes, & $\square$ \\
& Clinically \\
& Imaging
\end{tabular}

Biochemistry

Electrophysiology

Other

(please describe)

\section{$\nabla$}

$\triangle \mathrm{MRI}$ imaging of muscles may be able to direct variant testing, especially in uncertain/ambiguous cases.

$\triangle$ Histopathology, including electron microscopy of skeletal muscle. Besides 'pure' nemaline myopathy, variants in the known NEM genes have also been described in association with other congenital myopathies, which clinically can appear similar to nemaline myopathy. Pathologically, some patients have features in addition to nemaline bodies (eg, cores ${ }^{36}$ ). Patients with variants in the NEM genes may also have a myopathy without nemaline bodies, and may be diagnosed as having actin myopathy $\left(A C T A 1^{15}\right)$, intranuclear rod myopathy (ACTA1 eg ${ }^{37}$ ), congenital fibre type disproportion (OMIM \#255310; ACTA1;38 TPM339,40), cap disease (ACTA1; 41 TPM2; 42,43 TPM $3^{44,45}$ ) and distal myopathy $\left(\mathrm{NEB}^{46,47}\right)$. Variants in TPM2 and other nemaline myopathy genes can also cause distal arthrogryposis. ${ }^{48}$

Variants in other genes may also be associated with these additional histological features, for example nemaline myopathy with cores with variants in $R Y R 1,{ }^{49}$ and congenital fibre type disproportion with $R Y R 1^{50}$ or SEPN $1^{51}$ variants. Variants in TPM2 or TPM3 can cause congenital myopathies with neuromuscular transmission defects that can benefit from treatment with anticholinesterase therapy. ${ }^{52,53}$

Nemaline bodies can also be identified as secondary features, such as in mitochondrial disorders ${ }^{54}$ and HIV. 55

\subsubsection{Describe the burden of alternative diagnostic methods to the patient}

Nemaline myopathy is both a clinical and, significantly, a histopathological/electron microscopic diagnosis. Therefore, a thorough assessment including a detailed evaluation of clinical and pathological features should be performed along with genetic testing. As such, histopathology and electron microscopy are not diagnostic alternatives, rather prerequisites to genetic testing. Nevertheless, muscle biopsy is an invasive procedure, and appropriate histological and electron microscopic examination requires proximity to a specialised laboratory set up.
3.1.3 How is the cost effectiveness of alternative diagnostic methods to be judged?

Not applicable.

3.1.4 Will disease management be influenced by the result of a genetic test?

\begin{tabular}{|c|c|c|}
\hline No & $\square$ & \\
\hline Yes & $\otimes$ & \\
\hline & $\begin{array}{l}\text { Therapy } \\
\text { (please describe) }\end{array}$ & $\begin{array}{l}\text { Presently, the treatment of patients is based on symptom } \\
\text { management, which would occur regardless of the genetic } \\
\text { diagnosis. However, an accurate genetic diagnosis will } \\
\text { undoubtedly be extremely important for any causal therapies } \\
\text { once they are developed. }\end{array}$ \\
\hline & $\begin{array}{l}\text { Prognosis } \\
\text { (please describe) }\end{array}$ & $\begin{array}{l}\text { Varied, as nemaline myopathy can be severe (foetal or } \\
\text { congenital presentation) through to mild, }{ }^{56} \text { even with } \\
\text { variants in the same gene. For example, most patients } \\
\text { with ACTA1 variants affecting function die within their } \\
\text { first year of life, whilst some patients have a milder } \\
\text { phenotype compatible with survival into adulthood. }{ }^{13} \\
\text { However, even severely affected patients who survive the } \\
\text { first year of life may improve functionally in subsequent } \\
\text { years. Patients with the recessive TNNTI variant die } \\
\text { within } 2 \text { years of birth. The 'typical' subtype of nemaline } \\
\text { myopathy is considered non-progressive. }\end{array}$ \\
\hline & $\begin{array}{l}\text { Management } \\
\text { (please describe) }\end{array}$ & $\begin{array}{l}\text { Supportive-mechanical ventilation; night-time ventila- } \\
\text { tion; naso-gastric feeding; mobility aids; physiotherapy, } \\
\text { occupationVirual and speech therapy; surgery for scolio- } \\
\text { sis where needed. Cardiomyopathy is not normally pre- } \\
\text { sent; however, some instances have been reported with } \\
\text { ACTA1 variants. As an example, see ref. } 57 \text {. Genetic } \\
\text { testing is required for verifying the diagnosis and deter- } \\
\text { mining the mode of inheritance, which serves as a basis } \\
\text { for genetic counselling. }\end{array}$ \\
\hline
\end{tabular}

3.2 Predictive Setting: The tested person is clinically unaffected but carries an increased risk based on family history

(To be answered if in 1.10 'B' was marked)

Predictive testing is usually only applicable for the milder versions of nemaline myopathy, as most often the disease presents before, at or shortly after birth.

3.2.1 Will the result of a genetic test influence lifestyle and prevention?

If the test result is positive (please describe)

The positive test result may influence lifestyle choices for later onset of disease, for example deciding which career to pursue (eg, an office job compared with something physical), whether to travel at a young age when mobility is not affected compared with later in life and whether to have a house on one level as opposed to over multiple stories (eg, the latter would involve climbing lots of stairs which might become problematic). Respiratory precautions and self-monitoring for sleeprelated breathing problems may be advised. A positive test will greatly influence prevention, through the availability of prenatal or preimplantation diagnosis for the family. 
If the test result is negative (please describe)
A negative test result does not rule out the diagnosis of nemaline myopathy because of the possibility of currently unidentified causative genes or pathogenic variants not being identified in, for example, regions of $N E B$ that are difficult to sequence and/or map in next-generation sequencing. ${ }^{31}$ In this situation, prevention through genetic counselling is less informed. In terms of predictive testing, a negative result may influence lifestyle choices as indicated above, such as choice of occupation.
3.2.2 Which options in view of lifestyle and prevention does a person at-risk have if no genetic test has been done (please describe)? Not applicable.

3.3 Genetic risk assessment in family members of a diseased person (To be answered if in 1.10 'C' was marked)

\subsubsection{Does the result of a genetic test resolve the genetic situation in that family?}

Yes, if a variant/s is identified.

\subsubsection{Can a genetic test in the index patient save genetic or other tests in family members?}

Genetic testing would still most likely be performed for other family members, however, other tests such as skeletal muscle biopsy might be prevented.

\subsubsection{Does a positive genetic test result in the index patient enable a predictive test in a family member?}

Yes, but owing to very early disease onset in most cases, it is infrequently encountered.

\subsection{Prenatal diagnosis}

(To be answered if in 1.10 'D' was marked)

\subsubsection{Does a positive genetic test result in the index patient enable a prenatal diagnosis?}

Yes. In cases where dominant de novo variants have been identified in an affected child, genetic counselling may be difficult, as the recurrence risk is between 0 and $25 \%$ because of the possibility of gonadal mosaicism. However, prenatal genetic testing of an at-risk pregnancy is accurate.

\section{IF APPLICABLE, FURTHER CONSEQUENCES OF TESTING}

Please assume that the result of a genetic test has no immediate medical consequences. Is there any evidence that a genetic test is nevertheless useful for the patient or his/her relatives? (Please describe).

Yes, particularly if a variant/s are identified. An accurate genetic diagnosis often ends a lengthy diagnostic odyssey for the patient and their family, removing the psychological effects of an absent disease, and can sometimes influence possible prognosis. An accurate genetic diagnosis can crucially indicate the mode of inheritance and underpins genetic counselling, including options such as prenatal and preimplantation testing.

\section{CONFLICT OF INTEREST}

The authors declare no conflict of interest.

\section{ACKNOWLEDGEMENTS}

This work was supported by EuroGentest2 (Unit 2: 'Genetic testing as part of health care'), a Coordination Action under FP7 (Grant Agreement Number 261469), the European Society of Human Genetics, an Australian National Health and Medical Research Council (NH\&MRC) Fellowship APP1002147 and an Australian Research Council (ARC) Future Fellowship FT100100734.

1 Laing NG, Wilton SD, Akkari PA et al: A mutation in the alpha tropomyosin gene TPM3 associated with autosomal dominant nemaline myopathy. Nat Genet 1995; 9 75-79

2 Kiphuth IC, Krause S, Huttner HB, Dekomien G, Struffert T, Schroder R: Autosomal dominant nemaline myopathy caused by a novel alpha-tropomyosin 3 mutation. J Neurol 2010; 257: 658-660.

3 Tan P, Briner J, Boltshauser E et al: Homozygosity for a nonsense mutation in the alpha-tropomyosin slow gene TPM3 in a patient with severe infantile nemaline myopathy. Neuromuscul Disord 1999; 9: 573-579.

4 Wattanasirichaigoon D, Swoboda KJ, Takada F et al: Mutations of the slow muscle alpha-tropomyosin gene, TPM3, are a rare cause of nemaline myopathy. Neurology 2002; 59: 613-617

5 Lehtokari VL, Pelin K, Donner K et al: Identification of a founder mutation in TPM3 in nemaline myopathy patients of Turkish origin. Eur J Hum Genet 2008; 16: 1055-1061.

6 Pelin K, Hilpela P, Donner K et al: Mutations in the nebulin gene associated with autosomal recessive nemaline myopathy. Proc NatI Acad Sci USA 1999; 96: 2305-2310.

7 Lehtokari VL, Pelin K, Sandbacka M et al: Identification of 45 novel mutations in the nebulin gene associated with autosomal recessive nemaline myopathy. Hum Mutat 2006; 27: 946-956.

8 Anderson SL, Ekstein J, Donnelly MC et al: Nemaline myopathy in the Ashkenazi Jewish population is caused by a deletion in the nebulin gene. Hum Genet 2004; 115 $185-190$

9 Scoto M, Cullup T, Cirak S et al: Nebulin (NEB) mutations in a childhood onset dista myopathy with rods and cores uncovered by next generation sequencing. Eur J Hum Genet 2013: 21: 1249-1252.

10 Lehtokari VL, Kiiski K, Sandaradura SA et al: Mutation update: the spectra of nebulin variants and associated myopathies. Hum Mutat 2014; 35: 1418-1426.

11 Romero NB, Lehtokari VL, Quijano-Roy S et al: Core-rod myopathy caused by mutations in the nebulin gene. Neurology 2009; 73: 1159-1161.

12 Nowak KJ, Ravenscroft G, Laing NG: Skeletal muscle alpha-actin diseases (actinopathies): pathology and mechanisms. Acta Neuropathologica 2013; 125: 12-29.

13 Laing NG, Dye DE, Wallgren-Pettersson C et al: Mutations and polymorphisms of the skeletal muscle alpha-actin gene (ACTA1). Hum Mutat 2009; 30: 1267-1277.

14 O'Grady GL, Best HA, Oates EC et al: Recessive ACTA1 variant causes congenital muscular dystrophy with rigid spine. Eur J Hum Genet 2014; e-pub ahead of print 3 September 2014; doi:10.1038/ejhg.2014.169.

15 Nowak KJ, Wattanasirichaigoon D, Goebel HH et al: Mutations in the skeletal muscle alpha-actin gene in patients with actin myopathy and nemaline myopathy. Nat Genet 1999; 23: 208-212.

16 Jain RK, Jayawant S, Squier W et al: Nemaline myopathy with stiffness and hypertonia associated with an ACTA1 mutation. Neurology 2012; 78: 1100-1103.

17 Donner K, Ollikainen M, Ridanpaa M et al: Mutations in the beta-tropomyosin (TPM2) gene-a rare cause of nemaline myopathy. Neuromuscul Disord 2002; 12: 151-158.

18 Monnier N, Lunardi J, Marty I et al: Absence of beta-tropomyosin is a new cause of Escobar syndrome associated with nemaline myopathy. Neuromuscul Disord 2009; 19: 118-123.

19 Tajsharghi $\mathrm{H}$, Ohlsson M, Lindberg C, Oldfors A: Congenital myopathy with nemaline rods and cap structures caused by a mutation in the beta-tropomyosin gene (TPM2). Arch Neurol 2007; 64: 1334-1338.

20 Davidson AE, Siddiqui FM, Lopez MA et al: Novel deletion of lysine 7 expands the clinical, histopathological and genetic spectrum of TPM2-related myopathies. Brain 2013; 136: 508-521.

21 Mokbel N, Ilkovski B, Kreissl $\mathrm{M}$ et al: K7del is a common TPM2 gene mutation associated with nemaline myopathy and raised myofibre calcium sensitivity. Brain 2013; 136: 494-507.

22 Johnston JJ, Kelley RI, Crawford TO et al: A novel nemaline myopathy in the Amish caused by a mutation in troponin T1. Am J Hum Genet 2000; 67: 814-821.

23 van der Pol WL, Leijenaar JF, Spliet WG et al: Nemaline myopathy caused by TNNT1 mutations in a Dutch pedigree. Mol Genet Genomic Med 2014; 2: 134-137.

24 Sambuughin N, Yau KS, Olive M et al: Dominant mutations in KBTBD13, a member of the BTB/Kelch family, cause nemaline myopathy with cores. Am J Hum Genet 87 842-847.

25 Agrawal PB, Greenleaf RS, Tomczak KK et al: Nemaline myopathy with minicores caused by mutation of the CFL2 gene encoding the skeletal muscle actin-binding protein, cofilin-2. Am J Hum Genet 2007; 80: 162-167.

26 Ockeloen CW, Gilhuis HJ, Pfundt R et al: Congenital myopathy caused by a nove missense mutation in the CFL2 gene. Neuromuscul Disord 2012; 22: 632-639. 
27 Ong RW, Alsaman A, Selcen D et al: Novel cofilin-2 (CFL2) four base pair deletion causing nemaline myopathy. J Neurol Neurosurg Psychiatry 2014; 85: 1058-1060.

28 Ravenscroft G, Miyatake S, Lehtokari VL et al: Mutations in KLHL40 are a frequent cause of severe autosomal-recessive nemaline myopathy. Am J Hum Genet 2013; 93 : 6-18.

29 Gupta VA, Ravenscroft G, Shaheen R et al: Identification of KLHL41 mutations implicates BTB-Kelch-mediated ubiquitination as an alternate pathway to myofibrillar disruption in nemaline myopathy. Am J Hum Genet 2013; 93: 1108-1117.

30 Yuen M, Sandaradura SA, Dowling JJ et al: Leiomodin-3 dysfunction results in thin filament disorganization and nemaline myopathy. J Clin Invest 2014; 124 4693-4708.

31 Kiiski K, Laari L, Lehtokari VL et al: Targeted array comparative genomic hybridizationa new diagnostic tool for the detection of large copy number variations in nemaline myopathy-causing genes. Neuromuscul Disord 2013; 23: 56-65.

32 Wallgren-Pettersson C: Congenital nemaline myopathy: a longitudinal study. University of Helsinki: Helsinki, 1990

33 Wallgren-Pettersson C, Pelin K, Hilpela P et al: Clinical and genetic heterogeneity in autosomal recessive nemaline myopathy. Neuromuscul Disord 1999; 9: 564-572.

34 Wallgren-Pettersson C, Laing NG: Report of the 83rd ENMC International Workshop: 4th Workshop on Nemaline Myopathy, 22-24 September 2000, Naarden, The Netherlands. Neuromuscul Disord 2001; 11: 589-595.

35 Agrawal PB, Strickland CD, Midgett $C$ et al: Heterogeneity of nemaline myopathy cases with skeletal muscle alpha-actin gene mutations. Ann Neurol 2004; 56: 86-96.

36 Jungbluth $\mathrm{H}$, Sewry CA, Brown SC et al: Mild phenotype of nemaline myopathy with sleep hypoventilation due to a mutation in the skeletal muscle alpha-actin (ACTA1) gene. Neuromuscul Disord 2001; 11: 35-40.

37 Hutchinson DO, Charlton A, Laing NG, Ilkovski B, North KN: Autosomal dominant nemaline myopathy with intranuclear rods due to mutation of the skeletal muscle ACTA1 gene: clinical and pathological variability within a kindred. Neuromuscul Disord 2006; 16: 113-121.

38 Laing NG, Clarke NF, Dye DE et al: Actin mutations are one cause of congenital fibre type disproportion. Ann Neurol 2004; 56: 689-694.

39 Clarke NF, Kolski H, Dye DE et al: Mutations in TPM3 are a common cause of congenital fiber type disproportion. Ann Neurol 2008; 63: 329-337.

40 Lawlor MW, Dechene ET, Roumm E, Geggel AS, Moghadaszadeh B, Beggs AH: Mutations of tropomyosin 3 (TPM3) are common and associated with type 1 myofiber hypotrophy in congenital fiber type disproportion. Hum Mutat 2010; 31: 176-183.

41 Hung RM, Yoon G, Hawkins CE, Halliday W, Biggar D, Vajsar J: Cap myopathy caused by a mutation of the skeletal alpha-actin gene ACTA1. Neuromuscul Disord 2010; 20 238-240.

42 Lehtokari VL, Ceuterick-de Groote C, de Jonghe P et al: Cap disease caused by heterozygous deletion of the beta-tropomyosin gene TPM2. Neuromuscul Disord 2007; 17: 433-442.
43 Clarke NF, Domazetovska A, Waddell L, Kornberg A, McLean C, North KN: Cap disease due to mutation of the beta-tropomyosin gene (TPM2). Neuromuscul Disord 2009; 19: 348-351.

44 Ohlsson M, Fidzianska A, Tajsharghi $\mathrm{H}$, Oldfors A: TPM3 mutation in one of the original cases of cap disease. Neurology 2009; 72: 1961-1963.

45 De Paula AM, Franques J, Fernandez C et al: A TPM3 mutation causing cap myopathy. Neuromuscul Disord 2009; 19: 685-688.

46 Wallgren-Pettersson C, Lehtokari VL, Kalimo $\mathrm{H}$ et al: Distal myopathy caused by homozygous missense mutations in the nebulin gene. Brain 2007; 130: 1465-1476.

47 Lehtokari VL, Pelin K, Herczegfalvi A et al: Nemaline myopathy caused by mutations in the nebulin gene may present as a distal myopathy. Neuromuscul Disord 2011; 21: $556-562$.

48 Sung SS, Brassington AM, Grannatt K et al: Mutations in genes encoding fast-twitch contractile proteins cause distal arthrogryposis syndromes. Am J Hum Genet 2003; 72: 681-690.

49 Scacheri PC, Hoffman EP, Fratkin JD et al: A novel ryanodine receptor gene mutation causing both cores and rods in congenital myopathy. Neurology 2000; 55: 1689-1696.

50 Clarke NF, Waddell LB, Cooper ST et al: Recessive mutations in RYR1 are a common cause of congenital fiber type disproportion. Hum Mutat 2010; 31: E1544-E1550.

51 Clarke NF, Kidson W, Quijano-Roy S et al: SEPN1: associated with congenital fibertype disproportion and insulin resistance. Ann Neurol 2006; 59: 546-552.

52 Munot $\mathrm{P}$, Lashley $\mathrm{D}$, Jungbluth $\mathrm{H}$ et al: Congenital fibre type disproportion associated with mutations in the tropomyosin 3 (TPM3) gene mimicking congenital myasthenia. Neuromuscul Disord 2010; 20: 796-800.

53 Rodriguez Cruz PM, Sewry C, Beeson D et al: Congenital myopathies with secondary neuromuscular transmission defects; a case report and review of the literature. Neuromuscul Disord 2014; 24: 1103-1110.

54 Bethlem J, Arts WF, Dingemans KP: Common origin of rods, cores, miniature cores, and focal loss of cross-striations. Arch Neurol 1978; 35: 555-566.

55 Feinberg DM, Spiro AJ, Weidenheim KM: Distinct light microscopic changes in human immunodeficiency virus-associated nemaline myopathy. Neurology 1998; 50: 529-531.

56 Wallgren-Pettersson C, Laing NG: Report of the 70th ENMC International Workshop: nemaline myopathy, 11-13 June 1999, Naarden, The Netherlands. Neuromuscul Disord 2000; 10: 299-306.

57 D'Amico A, Graziano C, Pacileo G et al: Fatal hypertrophic cardiomyopathy and nemaline myopathy associated with ACTA1 K336E mutation. Neuromuscul Disord 2006; 16: 548-552. 